\title{
Gender Differences in Attitudes towards Prevention and Intervention Messages for Digital Addiction
}

\author{
John McAlaney ${ }^{1}$, Emily Arden-Close ${ }^{1}$, Raian $\mathrm{Ali}^{1}$ \\ ${ }^{1}$ Bournemouth University, UK \\ \{jmcalaney, eardenclose, rali\}@bournemouth.ac.uk
}

\begin{abstract}
It has been suggested that excessive use of the internet and digital devices can lead to digital addiction (DA). In contrast to other industries such as the alcohol industry there appears to be very little expectation on the software industry to position itself as a primary actor in the development of DA; even though software providers have unique capabilities to engage with users in real time and in a personalised way through multi-modal interactive and intelligent prevention and intervention messages. One aspect of personalisation that has been demonstrated to be of importance in relation to DA and other compulsive behaviours is gender. This study consisted of a series of initial exploratory interviews followed by a survey of 150 respondents and several same-sex focus groups, the latter of which was recruited from a university student sample. Thematic and quantitative analyses were then conducted on the data gathered. Overall participants welcomed the idea of DA prevention and intervention messages, although they also demonstrated a clear preference for any DA prevention and intervention messages system to be adaptive and context aware. Some gender differences were evident, such as in terms for acceptance of messages generated by friends or the preference for graphical messages. The results of this study suggest that DA prevention and intervention messages may be useful to and welcomed by individuals who use digital technologies excessively. However, these users also appear to have expectations of what a successful DA prevention and intervention messages system should be able to achieve. Further research is needed on this emergent topic.
\end{abstract}

Keywords: Digital Addiction; Prevention; Intervention; User Modelling; Personalization; Gender

\section{Introduction}

Digital connectivity is a characteristic of a modern society, but its excessive and obsessive use has led to concerns about what has been termed digital addiction [1]. The concept of digital addiction (DA) and whether this qualifies as a mental disorder is a somewhat controversial one, with it listed as an area that requires further attention in the most recent version of the Diagnostic and Statistical Manual of the American Psychiatric Association [2]. Nevertheless, there is evidence to indicate that excessive internet use can become a serious issue for some individuals. It has been suggested that the consequences of DA can include poor academic performance, reduced social and recreational activities, relationships breakups, low involvement in real-life communities, poor parenting, depression and lack of sleep [3, 4]. Estimates of DA vary according by country and according to the definition of DA being used, but it has been suggested $6 \%-15 \%$ of the general population meet the requirement of DA [5]. This figure rises to 
13-18\% among university students, who have been identified as a high-risk group for DA [5].

There is also a paucity of research that positions software and its developers as primary actors in the development of DA; with a few notable exceptions [6]. This contrasts with other behavioural domains such as alcohol or gambling. Industry bodies in these sectors engage in corporate social responsibility to address the potentially harmful or risky aspects of the products they are promoting, although it must be acknowledged that there is on-going debate about the underlying motivations of industry bodies in this work and how well they engage with it [7]. This corporate social responsibility can include activities such as financially supporting the provision of sources of further information or help for problematic use. An example of this would be the link to Drinkaware (www.drinkaware.co.uk) website that is included in many UK alcohol industry posters and television adverts.

In comparison to traditional prevention and intervention messages, such as that for alcohol and tobacco products, messages delivered via digital media is distinct in its ability to be issued in an interactive multimodal and intelligent style [6]. Unlike those traditional mediums for addiction, software can monitor the usage pattern of a user and decide upon whether there are symptoms of a problematic usage. This can occur in real time and whilst the behaviour is happening. For example, when a user is taking pictures and sharing these via their social networks in a hasty style accompanied using negative and emotive language. Similarly, software could be used to determine if an individual is compulsively checking for messages and social network site notifications. When a problematic usage is detected, software can generate a warning message and deliver it to the user using a suitable presentation and delivery style, e.g. through text messages, animations, avatars, progress bars, timers, a change in the colour scheme or a buzz indicating the status of the usage. This interactivity and intelligence in digital media give us space for customization and personalization of the DA messages.

When considering prevention and intervention strategies for any behaviour it is important to understand socio-demographic factors which may be relevant to the application and efficacy of such strategies. Gender is one such factor and is also something which can be relatively easily used as the basis for personalisation and customisation. Research into child and adolescent populations suggests that there are gender differences in the pathways for the development of DA, with boys being more likely to experience DA through online video gaming than girls, as well as being more likely to use the internet excessively to attempt to develop new friendships [8]. Gender has also been found to be an important factor in other behavioural domains that may relate to DA. Research into gambling for example has found that men tend to behave in riskier ways then women and exhibit higher levels of social anxiety [9]. Similarly, the importance of identifying gender specific factors that relate to prevention and relapse have been noted with regards to other addictive behaviours [10]. There remains though a lack of understanding on the role of gender in the prevention or intervention of DA.

The current study aimed to explore the issues around gender and prevention and intervention messages for DA to determine when or if gender specific approaches to prevention and intervention should be considered for this behaviour. This was done as part of a larger study into cultural differences in attitudes towards DA prevention and intervention messages. 


\section{$2 \quad$ Method and Research Settings}

This was a mixed methods study, composed of an initial exploratory stage based on interviews and then followed by a survey and several focus groups. Both the survey and the focus groups were conducted simultaneously using the model of triangulation described by Mayring [11]. The initial exploratory stage consisted of interviews with 11 participants, five males and six females, aged between 19 and 35 years old and holding differing views on the usefulness of prevention and intervention messages for DA. Four of them were professionals and seven were students.

The purpose of the survey was to expand upon the results obtained through the analysis of the interviews. The survey was disseminated through mailing lists to students at a university, professional mailing lists and the social media and mailing lists of the authors. Screening items were used to ensure that the respondents who participated in the survey could be considered to demonstrate a problematic usage of digital media. These items were based on the first three items of the CAGE measure [12], which was developed as a tool to quickly screen for alcohol use disorders. The four items of the original measure ask individuals if they have ever felt they should i) cut down on their drinking, ii) been annoyed by people criticising their drinking, iii) felt guilty about their drinking and iv) needed to drink in the morning to alleviate a hang-over (eye-opener). For the purposes of this study 'drinking' was replaced by 'use of social networks or gaming' for the first three items. The fourth item of the original CAGE measure was not adapted for use as this was not relevant to the topic of DA. A total of 151 surveys were returned, of which 146 were fully completed.

Two same sex focus groups were conducted in parallel to the survey, one including female participants and one including male participants. These participants were drawn from the student population of a university and were aged between 18 to 22 , with a range of academic disciplines represented. Informed consent was obtained from all individual participants included in each part of the study.

\section{$3 \quad$ Results}

The initial results on prevention and intervention messages, relating to the interviews and of the survey (with 72 completed responses), were presented at REFSQ 2015 conference [6]. The focus in that work was on the descriptive analysis and trends in prevention and intervention messages. It also presented a set of software engineering challenges for messages design. In this paper the focus is on the attitude and behaviour of digital technology users towards prevention and intervention messages and the gendereffect on that. Since the interview analysis was to provide a baseline for the survey and the focus groups, we will only report on those later studies in this paper.

\subsection{Study one: Thematic analysis of focus group discussions}

Each focus group was audio recorded and then transcribed by a research assistant. Thematic analysis was then applied using the method outlined by Braun and Clarke [13]. Several themes emerged from the thematic analysis, as discussed below.

Contextual awareness. Participants in both groups commented that they would want any prevention and intervention messages software to demonstrate an awareness of the 
context of their online activity. For example, participants stated that they would not want messages to appear in the middle of a pivotal task, particularly during online gaming. 'when it interrupts you at a crucial point. Where it full stops you and then it just makes you want to hate the idea more often even though it is a great concept' (male participant). Certain types of digital addiction were identified as being more amenable to notification systems, such as online shopping. "every time you made a purchase on this site and count it up and say, "Look you've spent this much, within this many days" and showed you it, and you'd be like "Wow, okay I've spent way too much money", (male participant). Overall participants wanted a message and notification system that understands when it is appropriate to deliver messages and when it is not, or to draw upon a phrase used by one of the female participants a system which is 'intuitive'.

Control. A strong theme throughout the discussion in both groups was the desire to control the appearance and operations of messages. It was felt that this would reduce some of the defensiveness that may be felt from receiving notifications 'If the person can choose what it says then that might be more effective too because they know what's most likely gonna be like "Ah I like that", (female participant). Participants also expressed the wish to be able to choose which software platforms they would receive notifications from. 'so like for me if Facebook notified me I'd be like "Okay go away I don't have a problem with you" if Tumblr notified me I'd be like "Oh yeah okay", (female participant). This was echoed by male participants, who commented that they perceived different platforms to have different requirements of what could be defined as addictive use. '....in comparison with console gaming umm because in console gaming you're, you're not kind of as, like immersed and it doesn't have like, also it doesn't have the stigma of a WoW gamer or a League gamer who stays up to like 6 the next day with their guild' (male participant).

Social comparisons. Participants were asked for their views on messages which would show them how their usage compares to their peers, or the norms of people of a similar age or profession as themselves. An issue raised by participants was that allowing people to compare their internet usage to their peers may result in individuals attempting to compete with one another to be the most 'addicted'. '... if we're dealing with students that can be a dangerous way of having pop ups because they might make a game out of it like who can play for the longest' (female student). 'It's naturally like a competition, be like “'Oh right, I'm gonna, yeah I'm gonna play it more, as long because oh he didn't play it as long"' (male participant). This reflects research into other risky behaviours, which has found for example that within American college student populations some groups such as Greek fraternities base their identity on the fact that that they perceive themselves to be the heaviest drinkers on campus [14]. Male participants also commented that people may use social comparisons to justify their own use, on the basis that others are more addicted than themselves. 'You'll probably think "Ah there's someone worse"" (male participant).

Message source. A related theme to social comparison was where the DA message would originate from. Both male and female participants expressed a preference for warnings and messages generated by software, although it appeared to be the case that this was because it was the least objectionable option to them. Participants stated that they would prefer not to receive messages from official sources such as the National 
Health Service (NHS), which they felt could come across as commercial adverts and would therefore be ignored. Female participants spoke about messages being sent from friends and family, in what they referred to as online 'interventions'. Female participants commented that this could be effective but also lead to resentment, although having the source of messages be anonymous was seen as a solution. '... because if I had it from friends or family yes it may affect me more but even if it was anonymous I'd be like as much as I appreciate their care it's not their business it's my time, I don't want you to bitch at me about this because you can't say it to my face' (female participant). The use of peer groups as a persuasive tool to combat DA has been explored in related work by the authors [15].

Message content. Female respondents agreed that warning messages based on risks to their public profile (e.g. social media posts that may be seen by prospective employers). 'if they like you they'll Google your name and the stuff comes up on Google and they see loads of pictures of you being out drunk every night they're not gonna wanna hire you' (female participant). This appeared to be less of an issue for male participants, who commented that a system such as this could become intrusive and repetitive. There was also a gender difference in preference over the use of figures and graphs, with female participants stating they would like this whereas male participants would not. 'you don't want going "Oh here's, you've been doing this, here's an amazing pie chart!" because you probably honestly just wouldn't care' (male participant). Similarly, male participants expressed a concern that notifications that came across as too medical could result in a sense that interventions were being held, and also that the act of focussing on digital addiction may lead individuals to self-diagnose. 'that's why you should never, it's like the same thing with never like Google your symptoms if you're ill because it normally comes up with "You have cancer". And then people naturally go "Oh no, I have cancer" kind of thing' (male participant).

Message style. A preference was expressed for informal, positive wording, as opposed to negative content. 'it's like give me a friendly one like "Just so you know you've been playing for 3 hours would you like a break?" and then you could select yes or no. So something that gives you an option to choose and isn't mean to you because then you get defensive' (female participant). Male respondents also commented that they would prefer messages phrased as suggestions rather than instructions. 'I think instead of it saying like "Take a break" it should be like "You've played for this amount of time. Why don't you take a break?" Because it just says like "Take a break" it's like "Nah"” (male participant). This theme is consistent with research into gambling, which suggests that personalised behavioural feedback may be an effective technique in reducing problem gambling [16].

\subsection{Study two: Quantitative analysis of survey}

A total of 151 participants responded to the survey, of whom 146 completed it. Of this $68(44 \%)$ identified as male and $80(52 \%)$ identified as female, with the remainder declining to identify a gender. Most participants $(57 \%)$ were aged between $18-25$, with the remainder (27\%) being aged $26-34$ or 35 and above (16\%). There were no statistically significant gender differences across age groups. 
Perceptions of social networking and gaming addictive use. Most participants (60\%) reported that they felt they should cut down on their use of social network sites or gaming. Females $(\mathrm{n}=55,68.8 \%)$ were found to be significantly more likely than males $(\mathrm{n}=$ $36,52.9 \%)$ to report this $\left(\chi^{2}=3.88, \mathrm{df}=1, \mathrm{p}<0.05\right)$.

Gender differences in attitudes to messages, and types of messages considered important. Gender differences in acceptance and type of messages, delivery style of warning messages, preferences for theme of content and preferences for choice of warning messages are presented in Table 1 (see Appendix). Messages considered important by $40 \%$ or more of participants are reported in Table 2 (see Appendix). Findings from both tables are discussed below.

Acceptance of warning messages and type. Overall the majority (79\%) of respondents reported that they were certain or somewhat likely to accept the use of warning messages. There were no significant gender differences in acceptance of warning messages (male: $51(75 \%)$, female $66(82.5 \%)$ ). Time spent online $(77 \%)$ and number of times a social networking site/ gaming platform were opened or visited $(51 \%)$ were the most accepted types of warning message. Females were significantly more likely to agree that warning messages based on consequences/ damage to their public profile $\left(\chi^{2}\right.$ $=8.9, \mathrm{df}=1, \mathrm{p}<0.01)$ would be useful.

Delivery style of warning messages. Time based progress bars (e.g. timers of usage so far) were reported to be the most preferred delivery style for warning messages $(58 \%)$, followed by pop-up notifications (48\%) and dynamic colourisation of interfaces $(45 \%)$.

Preferences for theme of content. Most respondents $(60 \%)$ reported that they would prefer warning message content that is positive and supportive and correspondingly reported that they would not prefer overly-negative content, with female respondents significantly more likely to report this $\left(\chi^{2}=4.14\right.$, $\left.\mathrm{df}=1, \mathrm{p}<0.05\right)$. Approximately one third (29\%) of respondents reported that they would prefer socially generated content (e.g. messages designed by other users, friends) Males were significantly more likely to state this than females $\left(\chi^{2}=4.36, \mathrm{df}=1, \mathrm{p}<0.05\right)$. Similarly, $28 \%$ of respondents stated that they would prefer precautionary content (e.g. warnings of potential addiction), with females more likely to state this than males $\left(\chi^{2}=5.3, \mathrm{df}=1, \mathrm{p}<0.05\right)$.

Preferences for choice of warning messages. The majority of respondents stated that they would like to control the frequency of receiving messages $(60 \%)$, and the format in which the messages is presented, e.g. graph, email or sound etc $(50 \%)$. There were no significant gender effects for preference of choice in warning messages.

\section{Thoughts on uses of software messages and consideration of software}

The extent to which individuals agreed with thoughts on use of software messages and consideration of software was assessed on a 5-point Likert scale from 1 (strongly agree) to 5 (strongly disagree). This information is presented in Table 3 (see Appendix) and discussed below.

Thoughts on uses of software messages. Most respondents $(65 \%)$ agreed with the statement that software developers are often unaware or uninterested in the addictive 
nature of software. In addition, most respondents (81\%) were also in agreement that knowing how a message was generated would increase their acceptance of the message. There were no significant gender effects on thoughts on uses of software messages.

Thoughts on consideration of software. Approximately a third of respondents strongly agreed that messages should take into account the type of device being used $(82 \%)$ and the stage of addiction of the user $(86 \%)$. Females were significantly more likely $(\mathrm{U}=1988, \mathrm{p}=.015)$ to report that they would wish warning message software to take into account the timing of use (e.g. peak use at weekends but lower use at other times).

\section{Discussion}

As determined by the survey conducted in the second stage of the study most respondents agreed that they sometimes felt they should cut down on their gaming or use of social network sites, with female participants significantly more likely to agree to this. Participants also agreed that there could be benefits of messages or warning messages, but as evident from the focus group discussions had several expectations about how this system should operate. Participants clearly preferred an intelligent and adaptive system that would understand the nature of their usage and only deliver messages at appropriate times in a non-intrusive style, although it was appreciated that there was a need for messages to capture attention against a background of competing stimuli. This conflict between how participants would prefer the prevention and intervention messages system to work and their understanding of how it would need to work in order to be effective was also evident with regards to control of the system. Participants expressed a strong desire to have control over any warning system they used, whilst acknowledging that any system that was too easy for the user to change could lead to it being ineffective.

As demonstrated in both the focus groups and the survey participants demonstrated a strong preference for message content that was not overly negative or directive. This is in keeping with research into prevention and intervention in other behavioural domains, which has noted that people will tend to react negatively if they feel are being pushed into an action [17]. This is known as reactance and has been documented in a number of studies $[18,19]$. Linked to this is the concept of the boomer-ang effect, in which an attempt to change a behaviour or attitude results in the individual engaging with their original behaviour or attitudes even more strongly, in an act of defiance against the attempt to change them [20].

Female participants reported in both the focus group and the survey that they would like messages which warn them of damage to their public profile due to inappropriate or hasty posting of messages on sites such as Facebook. This is consistent with research into impression management, that is how we attempt to control how we are perceived by others, which suggests that men engage more in self-enhancement and self-promotion than women do [21]. Overall it has been found that men tend to use what could be termed more aggressive impression management techniques, whereas women are more likely to use cautious and considered approaches [22]. This may in part explain why female participants in the current study appeared to be more receptive to messages warning of damage to their public profile, as they give more consideration to how a negative image could impact on their lives. This greater consideration by women may 
also explain the divide between male and female participants on the use of figures and graphs in warning messages, with female participants stating they would find this helpful whilst male participants commented that they would not.

The survey found that males were significantly more likely than females to agree that they would like message content that had been generated by friends, whereas in the focus groups female participants raised concerns that this would lead to resentment and tension between social network members. This is somewhat in contrast to previous research which suggests that females are more likely to rely on their social networks for support when faced with a challenge [23]. It may reflect the aforementioned results that female participants appeared to be more concerned with their public profile, and therefore perhaps more reluctant to be seen to have an issue. In addition, research suggests that women are more likely to develop digital addiction through social networking sites; whereas men are more likely to develop digital addiction through online gaming [24]. It may be that women are therefore less likely to wish to seek or receive support via a social networking site if the social networking site is itself the primary cause of their excessive internet use.

There were several limitations to the study. The focus groups participants consisted entirely of university students who, whilst as noted being a high-risk group for DA, are not representative of the general population. The survey consisted mainly of participants who are living in the UK, and therefore again may not be representative of the general population. Nevertheless, as exploratory research into an emergent area the study identified a number of gender related factors to be considered when designing messages for DA.

\section{$5 \quad$ Conclusion and Future Work}

This paper explored the difference and similarities in male and female perceptions and preferences of digital addiction prevention and intervention messages. Whilst some gender effects were evident there was overall a lack of differences in the views towards digital addiction prevention and intervention messages between male and female participants. Our future work will mainly take an experimental approach to tackle the nuances in the differences in accepting messages and their fit to different variables including gender, personality traits, usage style and contextual factors of the usage. While we do not expect a generalization, the understanding of the most common cases would help the design of default options when giving users the ability to customize prevention and intervention messages and thus save time and effort and maximize usability and potentially acceptance of such messages.

Acknowledgement. This research has been supported by IDEAL CITIES project funded by the European H2020-MSCA-RISE-2017 project, under grant agreement No. 778228 (IDEAL-CITIES).

\section{References}

1. Moreno, M.A., et al., Problematic internet use among US youth: a systematic review. Arch Pediatr Adolesc Med, 2011. 165(9): p. 797-805. 
2. American Psychiatric Association, Diagnostic and statistical manual of mental disorders. 2013: Washington, DC.

3. Kuss, D.J. and M.D. Griffiths, Online Social Networking and Addiction-A Review of the Psychological Literature. International Journal of Environmental Research and Public Health, 2011. 8(9): p. 3528-3552.

4. Echeburua, E. and P. de Corral, Addiction to new technologies and to online social networking in young people: A new challenge. Adicciones, 2010. 22(2): p. 91-95.

5. Young, K.S., X.D. Yue, and L. Ying, Prevalence estimates and etiologic models of internet addiction, in Internet Addiction: A Handbook and guide to evaluation and treatment, K.S. Young and C. Nabuco de Abreu, Editors. 2011, Wiley: Canada.

6. Ali, R., et al. The emerging requirement for digital addiction messages. in The 20th International Working Conference on Requirements Engineering: Foundation for Software Quality (REFSQ 2015). 2015. Essen, Germany.

7. Lyness, S.M. and J. McCambridge, The alcohol industry, charities and policy influence in the UK. European Journal of Public Health, 2014. 24(4): p. 557-561.

8. Lee, Y.H., C.H. Ko, and C. Chou, Re-visiting internet addiction among Taiwanese students: a cross-sectional comparison of students' expectations, online gaming, and online social interaction. Journal of Abnormal Child Psychology, 2015. 43(3): p. 589-599.

9. Wong, G., et al., Examining gender differences for gambling engagement and gambling problems among emerging adults. Journal of Gambling Studies, 2013. 29(2): p. 171-189.

10. Hoving, E.F., A.N. Mudde, and H. de Vries, Predictors of smoking relapse in a sample of Dutch adult smokers; the roles of gender and action plans. Addictive Behaviors, 2006. 31(7): p. 1177-1189.

11. Mayring, P., On generalization in qualitatively oriented research. Forum: Qualitative Social Research, 2007. 8(3).

12. Ewing, J.A., Detecting alcoholism. The CAGE questionnaire. Jama, 1984. 252(14): p. 1905-7.

13. Braun, V. and V. Clarke, Using thematic analysis in psychology. Qualitative Research in Psychology, 2006. 3: p. 77 - 101.

14. Carter, C.A. and W.M. Kahnweiler, The efficacy of the social norms approach to substance abuse prevention applied to fraternity men. Journal of American College Health, 2000. 49: p. 66 - 71.

15. Alrobai, A., et al., Online peer groups as a persuasive tool to combat digital addiction, in Persuasive Technology. 2016, Springer. p. 288-300.

16. Auer, M.M. and M.D. Griffiths, Personalized feedback in the promotion of responsible gambling: A brief overview. Responsible Gambling Review, 2014. 1(1): p. $27-36$.

17. Rhodewalt, F. and J. Davison, Reactance and the coronary-prone behavior pattern - the role of self-attribution in responses to reduced behavioral freedom. Journal of Personality and Social Psychology, 1983. 44(1): p. 220-228.

18. Rhodewalt, F. and M.J. Strube, A self-attribution-reactance model of recovery from injury in type-a individuals. Journal of Applied Social Psychology, 1985. 15(4): p. 330-344.

19. Tormala, Z.L. and R.E. Petty, What doesn't kill me makes me stronger: The effects of resisting persuasion on attitude certainty. Journal of Personality and Social Psychology, 2002. 83(6): p. 1298-1313. 
20. Lee, S.-J., et al., Development of a self-presentation tactics scale. Personality and Individual Differences, 1999. 26(4): p. 701-722.

21. Guadagno, R.E. and R.B. Cialdini, Gender differences in impression management in organizations: A qualitative review. Sex Roles, 2007. 56(7-8): p. 483-494.

22. Reevy, G. and C. Maslach, Use of social support: Gender and personality differences. Sex Roles, 2001. 44(7-8): p. 437-459.

23. Durkee, T., et al., Prevalence of pathological internet use among adolescents in Europe: demographic and social factors. Addiction, 2012. 107(12): p. 2210-2222.

\section{$7 \quad$ Appendix}

Table 1: Gender differences in attitudes to content, delivery style, theme and preferences of digital addiction messages

\begin{tabular}{|c|c|c|c|}
\hline \multirow{2}{*}{$\begin{array}{l}\text { Information relating to the mes- } \\
\text { sage }\end{array}$} & \multicolumn{2}{|l|}{ Agree (n\%) } & \multirow{2}{*}{$\begin{array}{l}\text { Comparison } \\
\left(\chi^{2}\right)\end{array}$} \\
\hline & $\begin{array}{l}\text { Male } \\
(n=68)\end{array}$ & $\begin{array}{l}\text { Female } \\
(\mathbf{n}=\mathbf{8 0})\end{array}$ & \\
\hline \multicolumn{4}{|l|}{ Which of the following information } \\
\hline \multicolumn{4}{|l|}{ would you like to see in the message? } \\
\hline Time spent online & $56(82.3 \%)$ & $60(75 \%)$ & 1.17 \\
\hline Times checked/visited software & $36(52.9 \%)$ & $50(50 \%)$ & 0.13 \\
\hline Features heavily used & $9(13.2 \%)$ & $12(15 \%)$ & 0.094 \\
\hline Potential risks & $15(22.1 \%)$ & $23(28.75 \%)$ & 0.86 \\
\hline Usage *bill* & $31(45.6 \%)$ & $34(42.5 \%)$ & 0.14 \\
\hline $\begin{array}{l}\text { Consequences/damage on your pub- } \\
\text { lic profile }\end{array}$ & $14(20.6 \%)$ & $35(43.8 \%)$ & $8.90 * *$ \\
\hline $\begin{array}{l}\text { Consequences on your online rela- } \\
\text { tionship with others }\end{array}$ & $14(20.6 \%)$ & $17(21.3 \%)$ & 0.01 \\
\hline Consequences on online contacts & $8(11.8 \%)$ & $13(16.3 \%)$ & 0.61 \\
\hline Consequences on real social life & $23(33.8 \%)$ & $31(38.8 \%)$ & 0.39 \\
\hline $\begin{array}{l}\text { Effects on physiological and mental } \\
\text { health }\end{array}$ & $34(50 \%)$ & $38(47.5 \%)$ & 0.09 \\
\hline $\begin{array}{l}\text { The ease and speed of information } \\
\text { spread once shared }\end{array}$ & $15(22.1 \%)$ & $23(28.8 \%)$ & 0.86 \\
\hline $\begin{array}{l}\text { Suggestions/advice on how to regu- } \\
\text { late the usage style }\end{array}$ & $22(32.4 \%)$ & $32(40 \%)$ & 0.93 \\
\hline $\begin{array}{l}\text { Suggestion/advice on potentially in- } \\
\text { teresting real life activities based on } \\
\text { your usage }\end{array}$ & $20(29.4 \%)$ & $26(32.5 \%)$ & 0.16 \\
\hline $\begin{array}{l}\text { Factual and proved statements about } \\
\text { the benefits of regulating usage style }\end{array}$ & $21(30.9 \%)$ & $26(32.5 \%)$ & 0.04 \\
\hline \multicolumn{4}{|l|}{ Delivery style of warning messages } \\
\hline Pop-up notifications & $32(47.1 \%)$ & $40(50 \%)$ & 0.13 \\
\hline Offline notifications & $9(13.2 \%)$ & $21(26.3 \%)$ & $3.85^{*}$ \\
\hline Hardware-based interactions & $14(20.6 \%)$ & $14(17.5 \%)$ & 0.23 \\
\hline
\end{tabular}


Personalised metaphors Analogy to traditional addiction Time-based progress status Sounds

Dynamic colouring of interfaces

Preferences for theme of content Non-repetitive content

Socially generated labels

Supportive content

Precautionary content

Non-overly negative content

$\begin{array}{lll}14(20.6 \%) & 30(37.5 \%) & 5.03^{*} \\ 7(10.3 \%) & 11(13.8 \%) & 0.41 \\ 40(58.8 \%) & 47(58.8 \%) & 0 \\ 8(11.8 \%) & 16(20 \%) & 1.84 \\ 29(42.6 \%) & 39(48.8 \%) & 0.55\end{array}$

$\begin{array}{lll}34(50 \%) & 39(48.8 \%) & 0.02 \\ 26(38.2 \%) & 18(22.5 \%) & 4.36^{*} \\ 37(54.4 \%) & 52(65 \%) & 1.72 \\ 13(19.1 \%) & 29(36.3 \%) & 5.31^{*} \\ 26(38.2 \%) & 44(55 \%) & 4.14^{*}\end{array}$

Preferences for choice of warning messages

Control type of information the label could contain

Control and specify time(s) the label will be delivered to me

Control the frequency of sending la- $45(66.2 \%) \quad 46(57.5 \%) \quad 1.17$

bels to me

Control how the label will be pre- $33(48.5 \%) \quad 42(52.5 \%) \quad 0.23$

sented to me

$\begin{array}{llll}\text { Control actions that trigger a label } & 31(45.6 \%) & 27(33.8 \%) & 2.16\end{array}$

$\begin{array}{llll}\text { Specify accepted sources of the label } & 24(35.3 \%) & 20(25 \%) & 1.86\end{array}$

Control strategy through which the $15(22.1 \%) \quad 23(28.8 \%) \quad 0.86$

labelling is decided

$\begin{array}{llll}\text { Software to be autonomous in form- } & 22(32.4 \%) & 22(27.5 \%) & 0.41\end{array}$

ing and delivering labels

$* \mathrm{p}<.05, * * \mathrm{p}<.01$ 
Table 2: Aspects of messages considered important by over $40 \%$ of participants

\begin{tabular}{ll}
\hline Aspect of messages & $\begin{array}{l}\text { Percentage con- } \\
\text { sidering it im- } \\
\text { portant }\end{array}$ \\
\hline $\begin{array}{l}\text { Which of the following information would you like to see in the } \\
\text { label? }\end{array}$ & $79 \%$ \\
Time spent online & $52 \%$ \\
Times checked/visited software & $49 \%$ \\
Effects on physiological and mental health & $44 \%$ \\
Usage *bill* & \\
& \\
Delivery style of warning messages & $59 \%$ \\
Time-based progress status & $49 \%$ \\
Pop-up notifications & $46 \%$ \\
Dynamic colouring of interfaces & \\
& \\
Preferences for theme of content & $62 \%$ \\
Supportive content & $50 \%$ \\
Non-repetitive content & $48 \%$ \\
Non-overly negative content & \\
& \\
Preferences for choice of warning messages & $62 \%$ \\
Control the frequency of sending labels to me & $51 \%$ \\
Control how the label will be presented to me & $42 \%$ \\
Control type of information the label could contain & $41 \%$ \\
Control and specify time(s) the label will be delivered to me & $39 \%$ \\
Control actions that trigger a label &
\end{tabular}


Table 3: Extent to which individuals agree with thoughts on use of software messages and what the software should consider when developing messages (means are presented with standard deviations in brackets)

\begin{tabular}{|c|c|c|c|}
\hline Statement & Male & Female & $\begin{array}{l}\text { Difference } \\
\text { (t-test) }\end{array}$ \\
\hline \multicolumn{4}{|l|}{$\begin{array}{l}\text { Thoughts on uses of software } \\
\text { messages }\end{array}$} \\
\hline $\begin{array}{l}\text { Software needs to inspire my } \\
\text { trust before I accept its offer of } \\
\text { labelling }\end{array}$ & $1.88(0.90)$ & $1.80(0.73)$ & 0.57 \\
\hline $\begin{array}{l}\text { Labelling may lead to less natural } \\
\text { use of the software and make me } \\
\text { lose closeness with it }\end{array}$ & $2.97(1.00)$ & $2.78(0.83)$ & 1.27 \\
\hline $\begin{array}{l}\text { Software can only have approxi- } \\
\text { mation and estimation about my } \\
\text { usage }\end{array}$ & $2.63(0.87)$ & $2.66(0.95)$ & -0.20 \\
\hline $\begin{array}{l}\text { Knowing how the label was gen- } \\
\text { erated and why will increase my } \\
\text { acceptance }\end{array}$ & $2.04(0.95)$ & $1.97(0.88)$ & 0.47 \\
\hline $\begin{array}{l}\text { I need to be able to know how my } \\
\text { usage data and reactions to labels } \\
\text { are used }\end{array}$ & $1.99(0.88)$ & $2.13(0.85)$ & -1.01 \\
\hline $\begin{array}{l}\text { I feel software developers/indus- } \\
\text { tries are often unaware of, or un- } \\
\text { interested in, the addictive nature } \\
\text { of their software and its conse- } \\
\text { quences }\end{array}$ & $2.60(1.34)$ & $2.26(1.27)$ & 0.13 \\
\hline \multicolumn{4}{|l|}{ When measuring and judging my } \\
\hline \multicolumn{4}{|l|}{$\begin{array}{l}\text { usage, forming a message and } \\
\text { delivering it, software should } \\
\text { consider }\end{array}$} \\
\hline $\begin{array}{l}\text { Progress or stage of addictive us- } \\
\text { age }\end{array}$ & $1.99(0.86)$ & $1.89(0.65)$ & 0.72 \\
\hline Type of devices being used & $2.03(0.97)$ & $1.87(0.70)$ & 1.15 \\
\hline Time space & $2.18(0.94)$ & $1.84(0.90)$ & $2.20 *$ \\
\hline Social context & $2.40(1.13)$ & $2.07(0.88)$ & $2.00 *$ \\
\hline Personal profile & $2.55(1.08)$ & $2.21(1.08)$ & 1.90 \\
\hline
\end{tabular}

